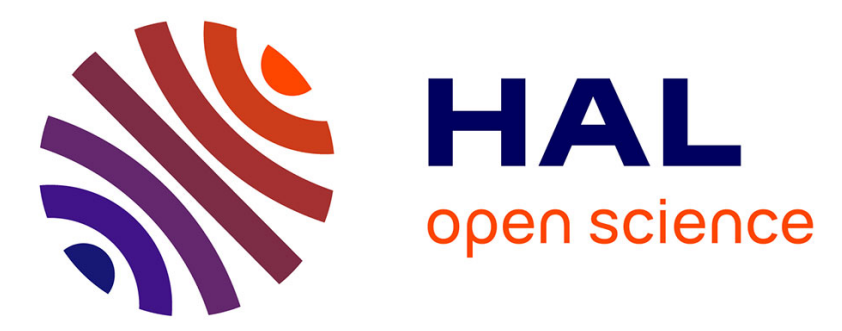

\title{
Structure and ionic conductivity of nitrated lithium disilicate (LiSiON) glasses
}

S.P. Singh, J.F. Schneider, S. Kundu, A.C.M. Rodrigues, P.P.G. de Mattos, E.D. Zanotto, J. Rocherullé, Patricia Bénard-Rocherullé, Ronan Lebullenger

\section{- To cite this version:}

S.P. Singh, J.F. Schneider, S. Kundu, A.C.M. Rodrigues, P.P.G. de Mattos, et al.. Structure and ionic conductivity of nitrated lithium disilicate (LiSiON) glasses. Materials Chemistry and Physics, 2018, 211, pp.438-444. 10.1016/j.matchemphys.2018.02.045 . hal-01774398

HAL Id: hal-01774398

https://hal-univ-rennes1.archives-ouvertes.fr/hal-01774398

Submitted on 6 Jul 2018

HAL is a multi-disciplinary open access archive for the deposit and dissemination of scientific research documents, whether they are published or not. The documents may come from teaching and research institutions in France or abroad, or from public or private research centers.
L'archive ouverte pluridisciplinaire HAL, est destinée au dépôt et à la diffusion de documents scientifiques de niveau recherche, publiés ou non, émanant des établissements d'enseignement et de recherche français ou étrangers, des laboratoires publics ou privés. 


\title{
Structure and ionic conductivity of nitrated lithium disilicate ( $\mathrm{LiSiON}$ ) glasses
}

Shiv Prakash Singha, b*, José Fabián Schneiderc, Swarup Kundu ${ }^{\mathrm{a}}$, Ana Candida Martins Rodrigues $^{\mathrm{a}}$, Paulo Parreira Gomes de Mattos ${ }^{\mathrm{a}}$, Edgar Dutra Zanotto ${ }^{\mathrm{a}^{* *}}$, Jean Rocherulléd, Patricia Bénard-Rocherulléd ${ }^{\text {, Ronan Lebullenger }}{ }^{d}$

${ }^{a}$ Vitreous Materials Laboratory (LaMaV), Department of Materials Engineering, Federal University of São Carlos, São Carlos-SP, Brazil.

${ }^{b}$ Institute of Nanotechnology, Karlsruhe Institute of Technology, 76344 Eggenstein Leopoldshafen, Germany

`Instituto de Física de São Carlos, Universidade de São Paulo, São Carlos, SP, 13.566-590, Brazil

${ }^{d}$ Glass and Ceramic Laboratory, Chemical Sciences Institute (ISCR) (UMR CNRS 6226), University of Rennes, France

\begin{abstract}
Lithium disilicate is a critical glass forming composition as it is the basis of some glass-ceramics and it is also a model glass for the study of homogeneous and heterogeneous crystal nucleation. Incorporation of nitrogen in this glass significantly changes its structure and affects different properties. In this paper, nitrided lithium disilicate glasses were prepared by partial substitution of oxygen up to $6 \mathrm{~atm} \% \mathrm{~N} /(\mathrm{N}+\mathrm{O})$. The modification of the silicate glass structure with nitrogen has been confirmed by Fourier transform infrared reflection (FTIR) spectroscopy. ${ }^{29} \mathrm{Si}$ NMR and ${ }^{7} \mathrm{Li}$ NMR have also been used to investigate the structural changes due to nitrogen incorporation. Substitution of oxygen by nitrogen with a higher coordination number (three) increases the connectivity of the glass. In fact, our NMR results indicate that nitrogen incorporation changes the $\mathrm{Q}^{\mathrm{n}}$ distribution ( $\mathrm{n}=$ average number of bridging oxygens to silicon) of the silicate structural units: $\mathrm{SiNO}_{3}, \mathrm{SiN}_{2} \mathrm{O}_{2}$ and $\mathrm{SiN}_{3} \mathrm{O}$, whereas there is no detectable change in the Li environment.
\end{abstract}


We measured the ionic $\left(\mathrm{Li}^{+}\right)$conductivity by impedance spectroscopy and found that the incorporation of nitrogen leads to a decrease in the activation energy for conduction, resulting in an increase of up to four-fold in the ionic conductivity of the most nitrided glass. We explained this high conductivity by the Anderson and Stuart model. This work provides renewed interest in improving and understanding the ionic conductivity in oxynitride glasses.

* Corresponding author

** Corresponding author.

E-mail addresses: spsingh67@gmail.com (S. P. Singh),dedz@ufscar.br (E. D. Zanotto)

\section{Introduction}

Lithium silicate glasses have been extensively studied for their interesting thermal, electrical, mechanical and structural properties [1-5], but also because these glasses present homogeneous (internal) nucleation in the volume $[6,7]$ serving as a model for crystallization studies. They are also the basis of some commercial glass-ceramics showing a numerous and relevant combination of properties $[8,9]$. On the other hand, it has always been a fascinating idea for researchers to improve properties of any glass by different processing techniques and compositional changes. Nitridation of oxide glasses is known to improve various properties, such as chemical durability, mechanical strength and electrical conductivity over their counter oxide glasses due to changes in their chemical bonding and structure [10, 11]. In nitrided silicate glasses, oxygen atoms in the $\mathrm{SiO}_{4}$ tetrahedra are partially replaced by nitrogen atoms. Accordingly, three coordinated nitrogen atoms in substitution to (two coordinated) oxygen results in a more connected structure than the corresponding oxide based silicate glasses, as we schematically show below:

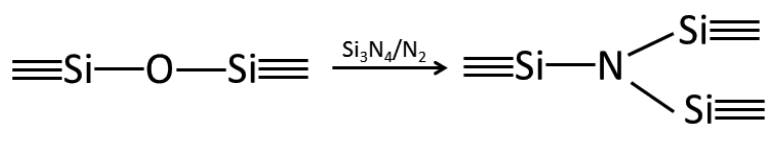


The overall outcome due to the incorporation of nitrogen into the glass structure is the increase in crosslinking through bonding of nitrogen with three silicon atoms and hence, a more rigid glass network is formed. Moreover, the electronegativity of oxygen is higher than that of nitrogen. Consequently, Si-O is partially replaced by the more covalent $\mathrm{Si}-\mathrm{N}$ bonding which favors the fast diffusion of the mobile $\mathrm{Li}^{+}$ion. Therefore, substitution of oxygen by nitrogen in glasses improves the electrical properties [12, 13]. According to some authors, the ionic conductivity increases due to the decrease of the electrostatic binding energy of the oxynitride glasses in comparison to oxide glasses $[10,12]$.

It is interesting to monitor the changes in the glass structure due to the substitution of oxygen by nitrogen using different techniques, such as ${ }^{29} \mathrm{Si}$ solid-state nuclear magnetic resonance (NMR) and Fourier transform infrared (FTIR) spectroscopies. These methods can be helpful to understand the possible arrangement of nitrogen atoms in the silicate network and provide information about structural changes which can help to describe the changes in the various properties of the oxynitride glasses.

Electrical properties of oxynitride glasses have been presented by different authors using structural and chemical bonding modification models due to the introduction of nitrogen by substitution of oxygen $[12,14,15]$. For instance, Reau et al. [12] have demonstrated an increase of $\mathrm{Li}^{+}$conductivity in lithium alumino silicate based oxynitride glasses with the increase in nitrogen content. Moreover, the conductivity and the activation energy for conduction of nitrided lithium alumino silicate and lithium silicate glass have been compared, and it was found that the conductivity of the last is higher than that of the lithium oxynitride aluminosilicate glasses. In another report, Muñoz et al. [15] have prepared oxynitride phosphate glasses by the ammonolysis process. Nitrogen incorporation resulted in a sharp increase in conductivity at low 
content of nitrogen. The increase in the electrical conductivity is explained [15] through the structural changes in lithium environment, but also by the increase of coordination number (two to three) and the nature of bonding (Si-O to Si-N). The effect of nitrogen on the conducting mechanism in lithium phosphorous oxynitride glasses has also been studied by Mascaraque et al. [14]. They proposed that the decrease of the bridging (BO) to non-bridging (NBO) oxygen ratio observed in X-Ray photoelectron spectroscopy is directly linked to the increase of ionic conductivity

$\mathrm{Li}^{+}$ion conductivity in silicate glasses is widely known. As a general rule, the activation energy decreases, and ionic conductivity increases with increasing the $\mathrm{Li}^{+}$concentration. However, there are scarce reports on nitrided lithium silicate glasses and to the best of our knowledge; there is no report on the ionic conductivity in nitrided lithium disilicate, an important "model" glass. Thus, in this paper, we explore the influence of nitrogen on the ionic conductivity in a lithium disilicate glass. We discuss the structural changes in the silicate glass structure due to the incorporation of nitrogen using FTIR, and ${ }^{29} \mathrm{Si}$ and ${ }^{7} \mathrm{Li}$ solid-state NMR. The difference in ionic conductivity in these oxynitride glasses is explained not only by taking into account modifications in the glass structure, but also by the nature of chemical bonding.

\section{Experimental procedure}

The $\mathrm{Li}_{2} \mathrm{O} .2 \mathrm{SiO}_{2}$ based oxynitride glasses were prepared by partial substitution of oxygen by nitrogen in the following atomic quantities: $\mathrm{N} /(\mathrm{N}+\mathrm{O})=0,1.5,3.0,4.5$ and 6.0. The glasses were prepared by melt-quenching in a glove box filled with nitrogen gas. The batches were made using reagent grade materials $\mathrm{Li}_{2} \mathrm{CO}_{3}$ (99\% ACS Reagent, Aldrich), quartz, $\mathrm{SiO}_{2}$ (99\% ACS Reagent, Merck) and $\mathrm{Si}_{3} \mathrm{~N}_{4}\left(99 \%\right.$, Merck). The mixture of raw materials was melted at $1300^{\circ} \mathrm{C}$ 
for $2 \mathrm{~h}$ using a molybdenum crucible inside the glove box in a nitrogen atmosphere. Glass samples of approximately $50 \mathrm{~g}$ were obtained by pouring the melts onto a molybdenum plate. The glasses were annealed at $400^{\circ} \mathrm{C}$ for $2 \mathrm{~h}$ to reduce the internal thermal stresses.

The glass transition $\left(\mathrm{T}_{\mathrm{g}}\right)$ and crystallization temperatures $\left(\mathrm{T}_{\mathrm{p}}\right)$ were determined from differential scanning calorimeter (DSC). The DSC experiments were performed using a Netzsch DSC 404 instrument from 30 to $1100{ }^{\circ} \mathrm{C}$ at a heating rate of $10^{\circ} \mathrm{C} / \mathrm{min}$ under air. Single glass pieces with $15 \mathrm{mg}$ mass were inserted in a covered platinum crucible for the above-described experiment.

Fourier transform infrared (FTIR) reflection spectra of polished bulk glasses were recorded with a Bruker Tensor 27 FTIR spectrometer after 32 scans and recorded in the range of 400-2000 $\mathrm{cm}^{-1}$.

High-resolution ${ }^{29} \mathrm{Si}$ and ${ }^{7} \mathrm{Li}-\mathrm{NMR}$ spectra were obtained using a Varian Unity INOVA spectrometer under a magnetic field of $9.4 \mathrm{~T}$ using powdered samples. For the ${ }^{29} \mathrm{Si}-\mathrm{NMR}$ experiments, the samples were spun at $5 \mathrm{kHz}$ in $7 \mathrm{~mm}$ zirconia rotors. Typical experimental parameters were: $\pi / 2$-pulse duration of $3.3 \mu$ s, recycling delays of $150 \mathrm{~s}$ and 600 collected scans. For the ${ }^{7} \mathrm{Li}$ NMR experiments, samples were spun at $9 \mathrm{kHz}$ in $4 \mathrm{~mm}$ silicon nitride rotors. Typical experimental parameters were: $\pi / 2$-pulses of $2.0 \mathrm{~ms}$, recycle delays of $1000 \mathrm{~s}$ and collected 64 scans. The chemical shift standards were a kaolinite sample for ${ }^{29} \mathrm{Si}(-91.5 \mathrm{ppm}$ concerning TMS $)$ and $\mathrm{LiCl} 1 \mathrm{M}$ solution for ${ }^{7} \mathrm{Li}(0 \mathrm{ppm})$. The electrical conductivity was measured by impedance spectroscopy (IS) using a Solartron, SI1260 impedance meter. Rectangular shaped samples for conductivity were polished on parallel sides, and gold was sputtered on both surfaces for 3 minutes on each side. The electrical measurements were 
performed in air with a two-point sample holder from 323 to $423 \mathrm{~K}$ with an applied voltage of $500 \mathrm{mV}$ in the frequency range from $1 \mathrm{MHz}$ to $1 \mathrm{~Hz}$.

\section{Results and discussion}

\subsection{Differential scanning calorimetry (DSC)}

A typical DSC graph is shown in Fig. 1 for the lithium disilicate glass. The glass transition temperature $\left(\mathrm{T}_{\mathrm{g}}\right)$ and crystallization peak temperature $\left(\mathrm{T}_{\mathrm{p}}\right)$ are $457{ }^{\circ} \mathrm{C}$ and $655{ }^{\circ} \mathrm{C}$, respectively. All glasses were annealed at $400{ }^{\circ} \mathrm{C}$ for $2 \mathrm{~h}$, which is well below the glass transition temperature to avoid any crystallization process. $T_{g}$ and $T_{p}$ increased with the addition of nitrogen and are reported elsewhere [16].

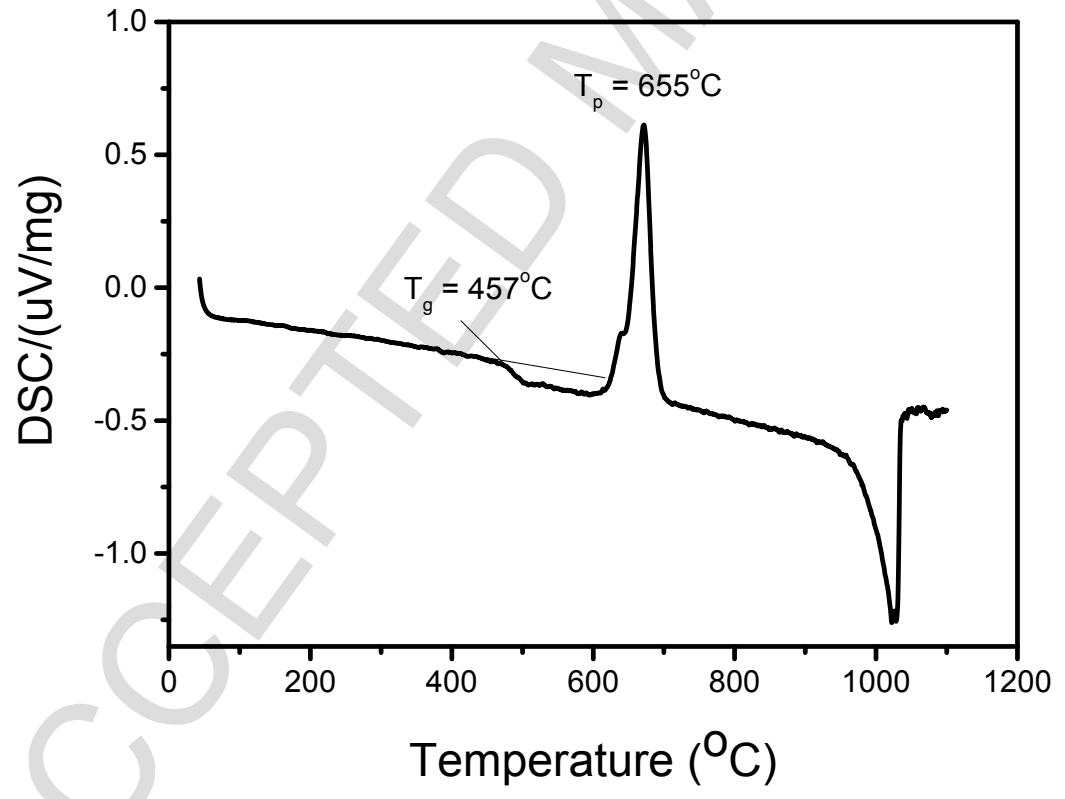

Fig. 1. Differential scanning calorimetry (DSC) thermogram of the lithium disilicate base glass (pure oxide glass). 


\subsection{Fourier transform infrared reflection (FTIR) spectroscopy}

The results of FTIR spectroscopy tests are shown in Fig. 2 for the glasses containing 0, 3, 4.5 and 6 atm $\% \mathrm{~N} /(\mathrm{N}+\mathrm{O})$. The glass spectra show reflection bands at 634, 666, 709, 823 and $979 \mathrm{~cm}^{-1}$. The broad band centered at $666 \mathrm{~cm}^{-1}$ of the pure oxide glass gradually bifurcated into two bands at 634 and $709 \mathrm{~cm}^{-1}$ with the incorporation of nitrogen into the glass. This change in the spectral profile with the concentration of nitrogen confirms that there is a change in the nature of the bonds of the glass structure. The band at $666 \mathrm{~cm}^{-1}$ is assigned to the stretching vibration of $\mathrm{Si}-\mathrm{O}-\mathrm{Si}$ of tetrahedral $\left[\mathrm{SiO}_{4}\right]$ units [17]. The introduction of nitrogen into the glass structure resulted in the development of two types of bands, $\mathrm{Si}-\mathrm{O}$ and $\mathrm{Si}-\mathrm{N}$. The shift of the Si-O band is attributed to higher disorder or bond strain into the tetrahedral $\left[\mathrm{SiO}_{4}\right]$ unit. The band at higher energy, $709 \mathrm{~cm}^{-1}$, is assigned to Si-N stretching vibration $[18,19]$. The spectral profiles of other bands are similar in all glasses. Bands at 823 and $979 \mathrm{~cm}^{-1}$ are also attributed to the stretching vibration of Si-O-Si [18]. The formation of Si-N bond in the glass structure may affect the glass properties. Moreover, the substitution of oxygen by nitrogen also results in an increase of the connectivity of the glass network through the bonding of nitrogen with three silicon atoms. Such increase in the connectivity may cause strain in the glass network. 


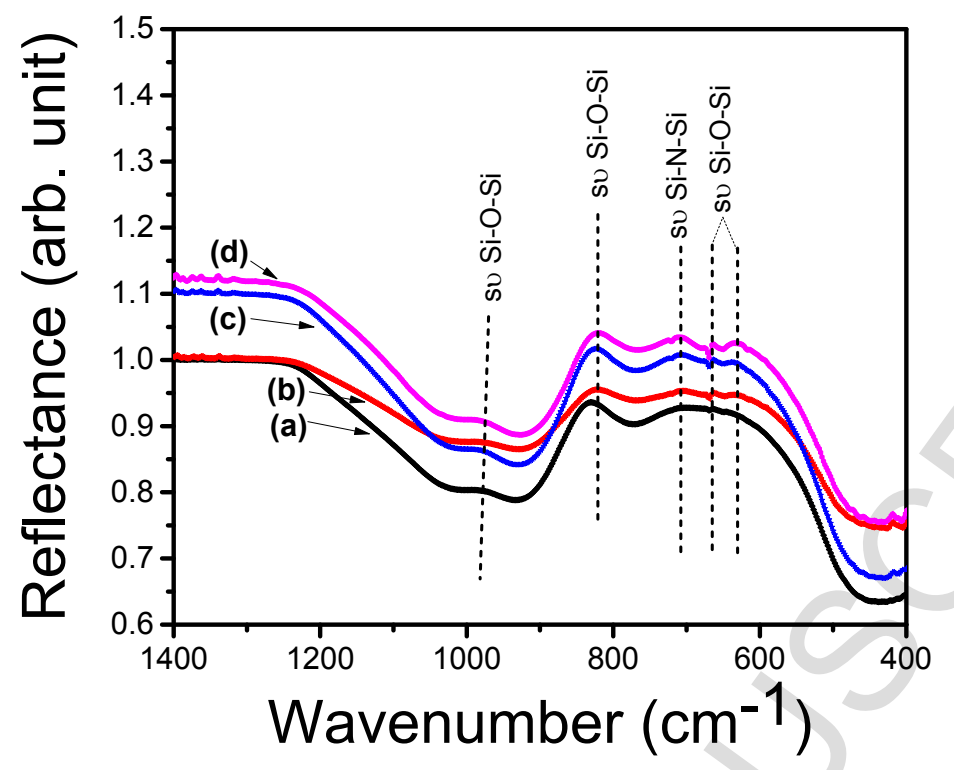

Fig. 2. FTIR spectra of the glass (a) 0, (b) 3, (c) 4.5 and (d) 6 atm \% N/N+O.

\section{3. ${ }^{29} \mathrm{Si}$ and ${ }^{7} \mathrm{Li}$ solid-state nuclear magnetic resonance (NMR)}

The ${ }^{29} \mathrm{Si}$ and ${ }^{7} \mathrm{Li}$ solid-state NMR spectra of the set of the oxynitride glasses are shown in Fig. 3 and Fig. 4, respectively. The ${ }^{29} \mathrm{Si}-\mathrm{NMR}$ spectra show gradual changes in the spectral profile of the nitrogenated glasses compared to the base glass. Least-square fittings of Gaussian functions were carried out to de-convolute the spectra. Three resonances can be identified in the nitrogen-free glass, with average isotropic chemical shifts $\delta_{\text {iso }}$ of $-102 \mathrm{ppm},-87 \mathrm{ppm}$ and $-76 \mathrm{ppm}$, corresponding to $\mathrm{Q}^{4}, \mathrm{Q}^{3}$ and $\mathrm{Q}^{2}$ tetrahedral species, respectively [20-22]. The numbers 2,3 and 4 in $\mathrm{Q}^{2}, \mathrm{Q}^{3}, \mathrm{Q}^{4}$ are assigned as the average numbers of bridging oxygens to the silicon atoms. Fig. 3 shows that gradual incorporation of nitrogen to the lithium disilicate glass causes a general broadening of the spectral bands and an increase in the spectral intensity in the region of higher $\delta_{\text {iso. }}$ The incorporation of nitrogen in the glass structure creates $\mathrm{SiO}_{4-n} \mathrm{~N}_{n}$ structural units. The vertical bars in Fig. 3 locate the typical region for ${ }^{29} \mathrm{Si}-\delta_{\text {iso }}$ for these structural units according to 
literature data [23]. The increase in the spectral intensity on the left side of the spectra, between $80 \mathrm{ppm}$ and $-60 \mathrm{ppm}$, is consistent with the presence of $\mathrm{SiN}_{2} \mathrm{O}_{2}$ and $\mathrm{SiN}_{3} \mathrm{O}$ but quantification of $\mathrm{SiO}_{4-\mathrm{n}} \mathrm{N}_{\mathrm{n}}$ species from these spectra is not possible due to the strong overlap between the resonances. ${ }^{7} \mathrm{Li}$ NMR was carried out in all glasses to determine the effect of nitrogen inclusion on the lithium sites. Fig. 4 shows the ${ }^{7} \mathrm{Li}$ NMR spectra for the 0 and 6 atm $\%$ of $\mathrm{N} /(\mathrm{N}+\mathrm{O})$ glasses, which are identical $\left(\delta_{\text {iso }}=-0.16 \mathrm{ppm}, \mathrm{FWHM}=3.8 \mathrm{ppm}\right)$. This result supports the idea that nitrogen is bonded only to silicon atoms and not directly to lithium. Therefore, the structural environment of Li, which is determined essentially by the nearest non-bridging oxygens, is not affected by the addition of nitrogen.

Fig. 5 shows a schematic representation of the structural units described above, with three-fold coordinated nitrogen bonding only to $\mathrm{Si}$, in substitution of $\mathrm{O}$. On the other hand, there is still a possibility that the invariance of ${ }^{7} \mathrm{Li}-\mathrm{NMR}$ spectra results from the combination of low concentration of $\mathrm{N}$ and the low intrinsic sensitivity of the ${ }^{7} \mathrm{Li}$ chemical shift to variations in more remote bonds. Muñoz et al. [15] have observed an increase in the chemical shift of the ${ }^{6} \mathrm{Li}$ NMR resonances with nitrogen in a lithium oxynitride phosphate (LiPON) glass which has been related to a decrease in the average $\mathrm{Li}^{+}$coordination number and to an increase in the covalent character of Li-O bonds. In contrary to Muñoz's report, we did not observe any chemical shift of the ${ }^{7} \mathrm{Li}$ in this study, which suggests that the environment of $\mathrm{Li}^{+}$is not affected due to the nitridation of the glasses. 

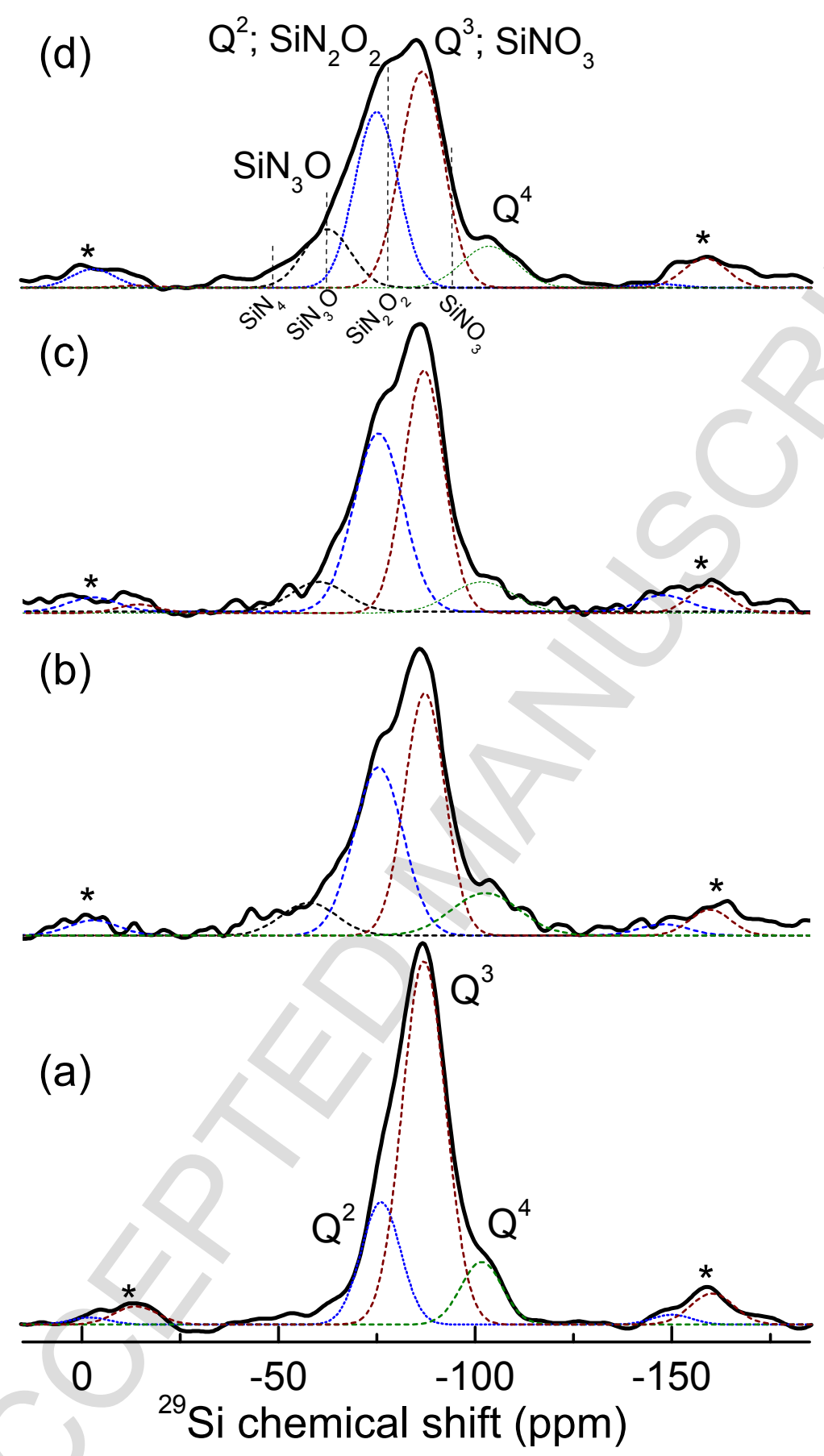

Fig. 3. ${ }^{29} \mathrm{Si}$ NMR spectra of the glass (a) 0, (b) 3, (c) 4.5 and (d) 6 atm \% N/N+O. Dotted curves: least-square fitting of Gaussian functions. Vertical lines: typical chemical shift values expected for $\mathrm{SiO}_{4-\mathrm{n}} \mathrm{N}_{\mathrm{n}}$ units. Asterisks: spinning side-bands. 


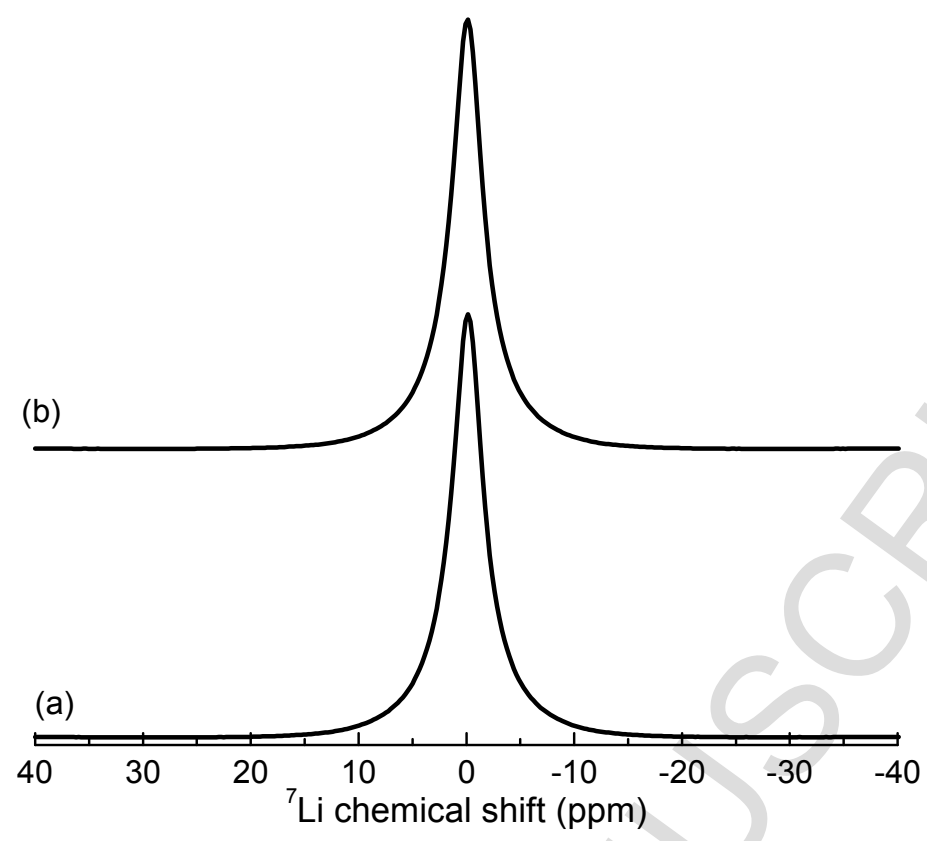

Fig. 4. ${ }^{7} \mathrm{Li}$ NMR spectra of the glass (a) 0and (d) $6 \mathrm{~atm} \% \mathrm{~N} / \mathrm{N}+\mathrm{O}$.

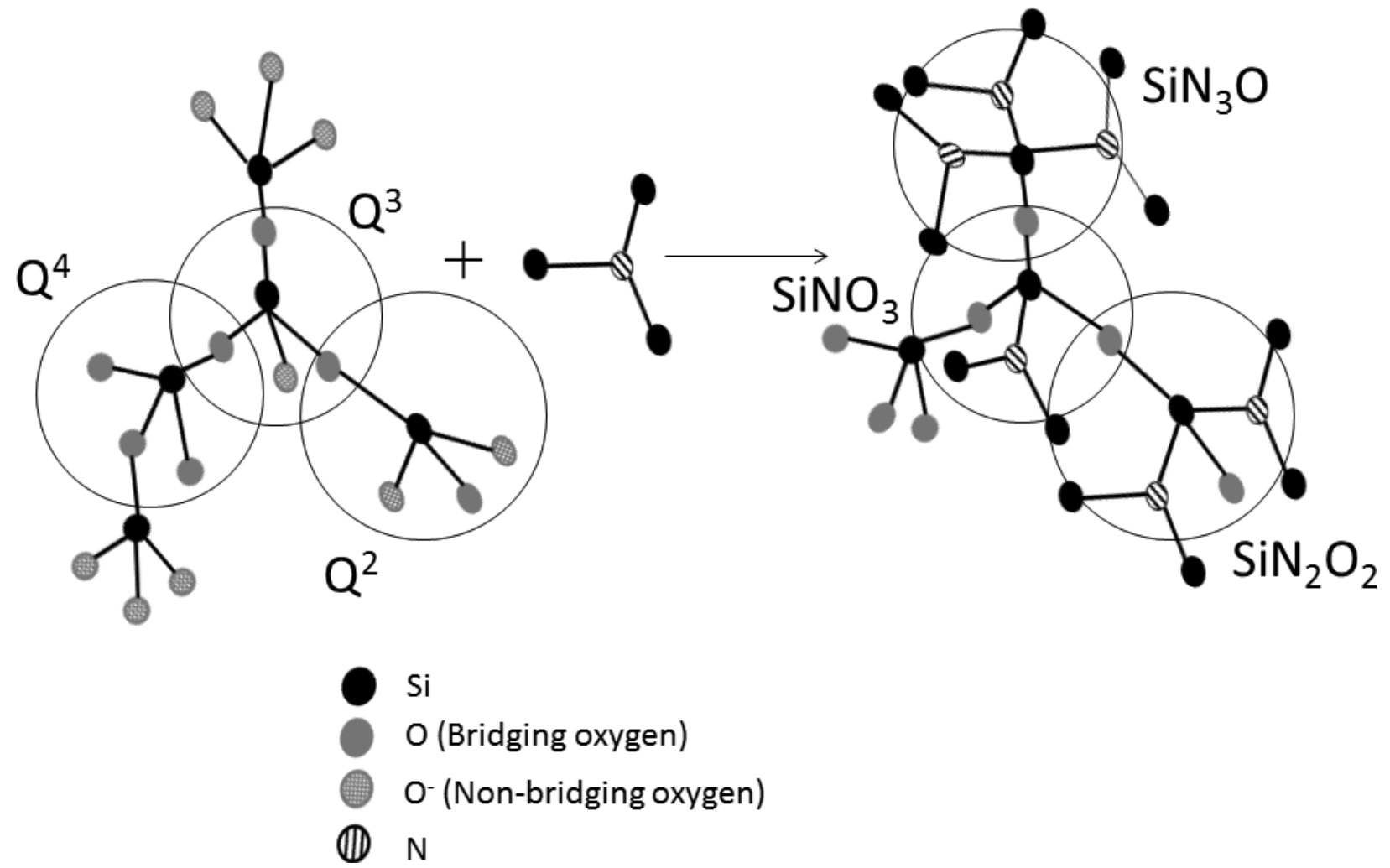

Fig. 5. Schematic representation of the structure of the oxynitride glass. 


\subsection{Ionic conductivity due to $\mathrm{Li}^{+}$}

Impedance spectroscopy data were collected and plotted in the impedance complex plane, the so-called Nyquist diagram. A single skewed semicircle, which passes through the origin of the complex plane, is found for all samples in the measured temperature range. The intersection at low frequency on the real axis corresponds to the resistance (R), or in the present case, where the geometrical factor has been taken into consideration, to the resistivity ( $\rho$ ) of the sample. As an example, the Nyquist plots at room temperature are shown in Fig. 6, in which the real $\left(Z^{\prime}\right)$ and imaginary $\left(Z^{\prime \prime}\right)$ parts of impedance, were multiplied by $\mathrm{S} / l(\mathrm{~S}=$ area of the sample in contact with the electrode, $l=$ thickness of the sample) to allow comparison between all samples.

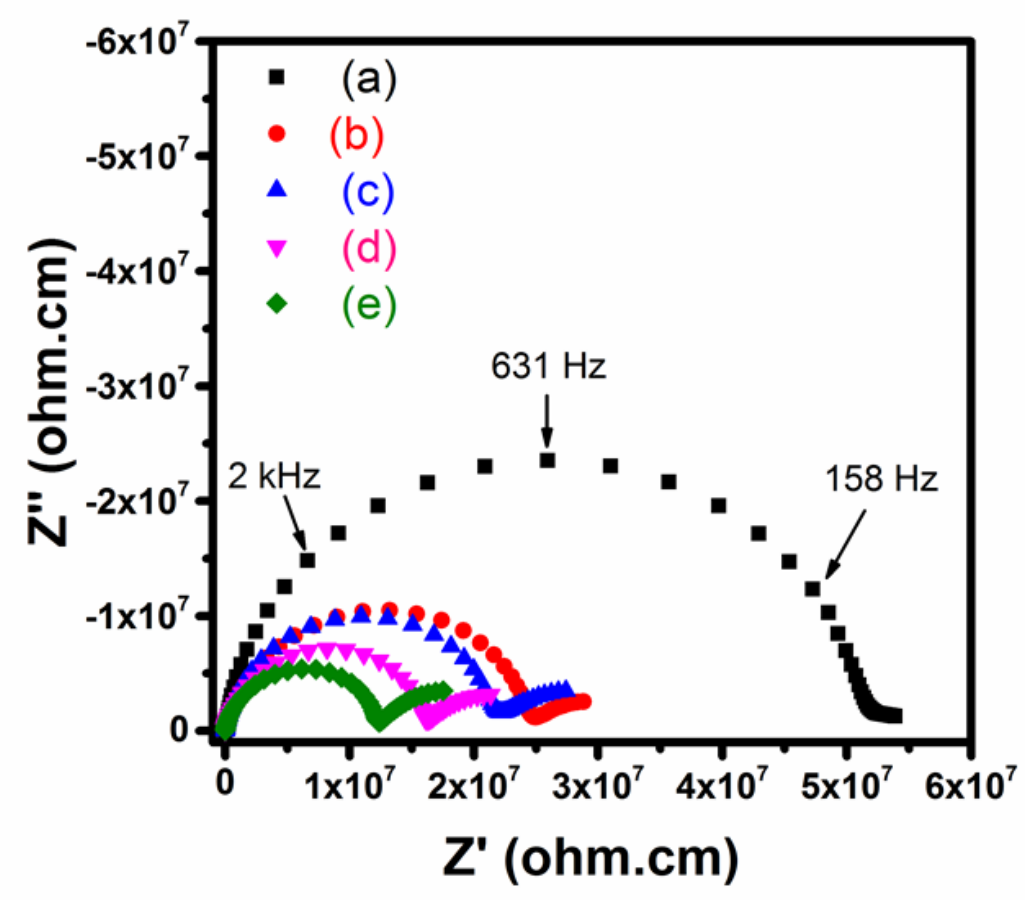

Fig. 6. Nyquist plot for samples containing (a) 0 , (b) 1.5 , (c) 3.0 , (d) 4.5 and (e) $6.0 \mathrm{~atm} \%$ $\mathrm{N} /(\mathrm{N}+\mathrm{O})$. 
Figure 6 shows that the resistivity $(\rho)$ of the samples decreases with the nitrogen content. Using these plots, the ionic conductivity $(\sigma)$ was calculated at different temperatures by $\sigma=1 / \rho$. The ionic conductivity of glasses normally follows an Arrhenius equation:

$$
\sigma=\sigma_{0} \exp \left(-\frac{E_{a}}{k T}\right)
$$

where $\sigma_{0}$ is a pre-exponential factor, $\mathrm{E}_{\mathrm{a}}$ is the activation energy for $\mathrm{Li}^{+}$conduction, $k$ is the Boltzmann constant, and $\mathrm{T}$ is the absolute temperature. Therefore, the ionic conductivity as a function of inverse temperature is plotted in Fig. 7. The activation energy was calculated from the slope of the linear regression (solid straight line) of the Arrhenius plot. Its evolution with the nitrogen content is shown in Fig. 8 along with the pre-exponential term $\sigma_{0}$ of expression (1)

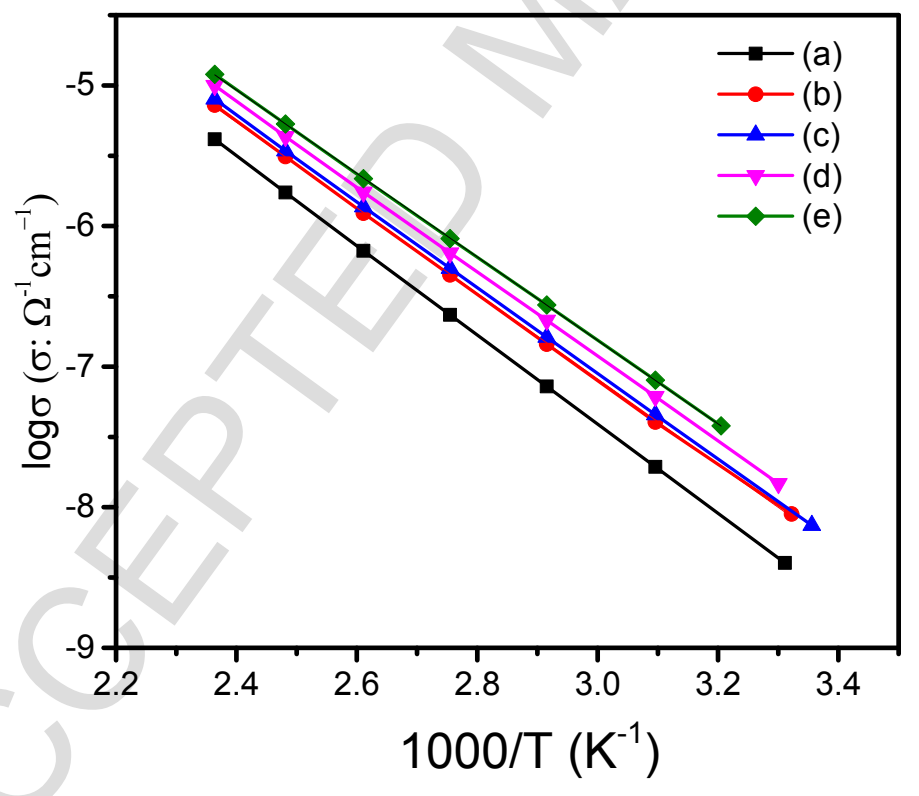

Fig. 7. Arrhenius plots of the oxynitride glasses containing (a) 0, (b) 1.5, (c) 3.0, (d) 4.5 and (e) 6 at $\% \mathrm{~N} /(\mathrm{N}+\mathrm{O})$ as a function of inverse temperature. 


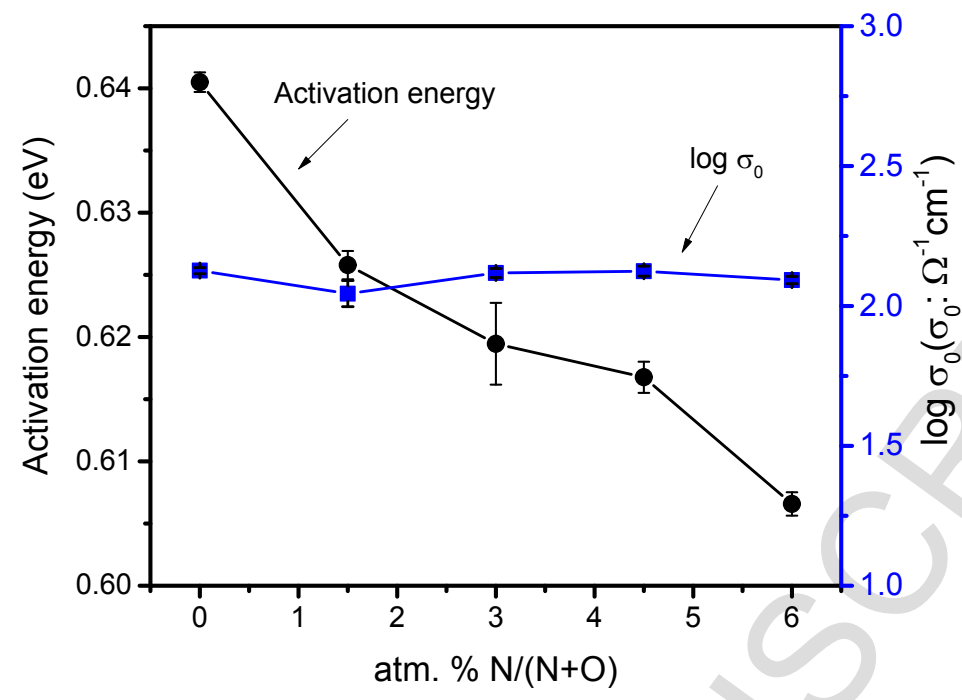

Fig. 8. The activation energy of the oxynitride glasses and the pre-exponential factor $\left(\sigma_{0}\right)$ of the Arrhenius equation plotted as a function of $\mathrm{N} /(\mathrm{N}+\mathrm{O})$. The bars indicate the mathematical error from the linear regression.

Figure 8 shows that the logarithm of the pre-exponential factor of the Arrhenius expression $\sigma_{0}$, remains close to typical values of 2 found [24] and also calculated [25] for lithium ionic conductors. Therefore, the decrease of the activation energy as a function of nitrogen content leads to an increase in ionic conductivity at room temperature as shown in Fig. 9. 


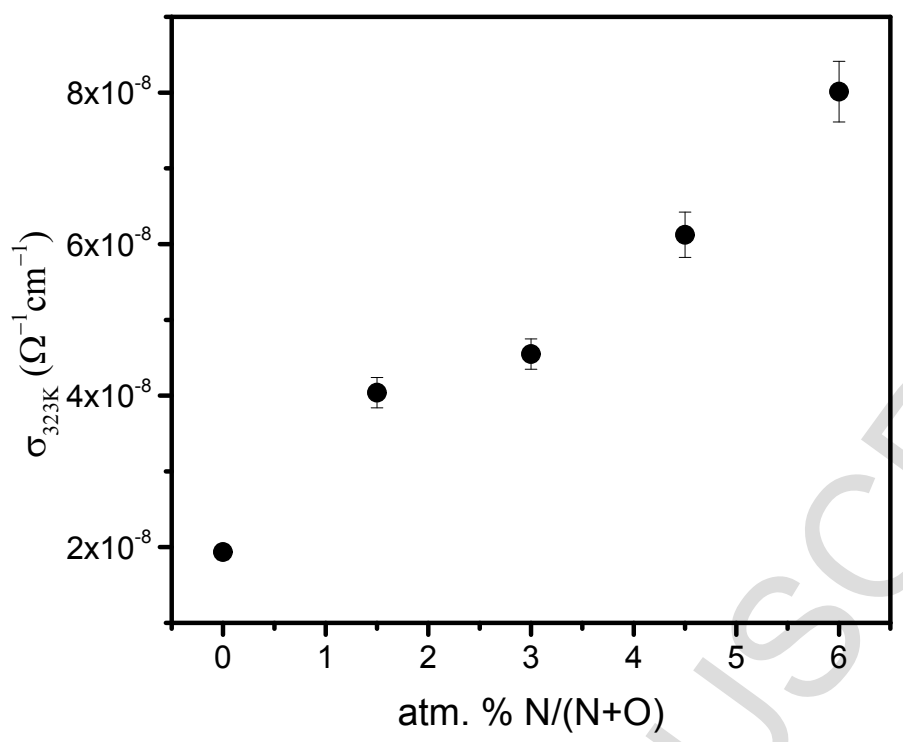

Fig. 9. $\mathrm{Li}^{+}$ionic conductivity of the oxynitride glasses at $323 \mathrm{~K}$ as a function of $\mathrm{N} /(\mathrm{N}+\mathrm{O})$.

An increase in ionic conductivity and decrease in the activation energy has already been observed in other oxynitride glasses $[10,11]$ and also in nitrided phosphate glasses [15]. This change in the ionic conductivity may be correlated to the structural changes in the glass matrix detected by FTIR spectroscopy and solid-state NMR techniques. In fact, the introduction of nitrogen changes the $\mathrm{Q}^{\mathrm{n}}$ structure to $\mathrm{SiO}_{3} \mathrm{~N}, \mathrm{SiO}_{2} \mathrm{~N}_{2}, \mathrm{SiON}_{3}$, as depicted in the Fig. 5. Moreover, the oxynitride glasses show more structural rigidity than the oxide glasses due to their higher structural connectivity as a result of the introduction of three coordinated nitrogen atoms, in substitution of two-coordinated oxygen atoms.

Munoz et al. [15] have studied the influence of the nitrogen content in the electrical conductivity of lithium phosphorus oxynitride glasses. They found that the ionic conductivity increases for low content of nitrogen $(\mathrm{N} / \mathrm{P}<0.15)$ and stabilizes for $\mathrm{N} / \mathrm{P}>0.15$. They proposed that the increase in electrical conductivity for low nitrogen contents is due to the increase in the 
amount of non-bridging oxygens. Moreover, the increased cross-linking density of the glass network results in the creation of conduction paths with lower activation energy. In case of high nitrogen contents, the increase in the covalent character of Li-O bonds as seen by ${ }^{6} \mathrm{Li}$ NMR may counteract the lithium mobility giving rise to a quite constant value of electrical conductivity. In another study of ionic conductivity in the glass system of Na-Si-O-N, Unuma et al. [26] have shown an increase in the conductivity upon nitridation. They explained this behavior by the fact that the Si-N bond has higher covalency than the Si-O bond. It results that the negatively charged electron cloud of anions may be more highly susceptible to deformation than that of pure oxide glass. Hence, the electrostatic force applied on a sodium ion would be reduced when the glass is nitraded and causes the reduction of the activation energy. The above studies show that it is not simple to infer the mechanism of the ionic conductivity increase in lithium disilicate oxynitride glasses. Therefore, we will use the model developed by Anderson and Stuart [27], which discusses the parameters affecting the activation energy for ionic conduction in a glassy ionic conductor.

According to this model, the activation energy $\left(E_{a}\right)$ for ionic conduction depends on two terms, i.e. the network strain energy $\left(E_{s}\right)$ and the electrostatic binding energy $\left(E_{b}\right)$ as $E_{a}=E_{s}+E_{b}$. The strain energy $\left(E_{s}\right)$ is the energy required to create a doorway for the mobile ion passing through the matrix and can be written as [27]

$$
E s=\frac{\pi}{2} G_{0} \lambda\left(r-r_{d}\right)^{2}
$$

where $G_{o}$ is the (infinite frequency) shear modulus of the matrix, $\lambda$ is the effective jump distance between the consecutive cation $\left(\mathrm{Li}^{+}\right)$sites, $r$ is the radius of the mobile cation and $r_{d}$ is the doorway radius available in a certain glass composition. Thus, the strain energy is the energy necessary to enlarge the available doorway in a certain glass composition, in order to allow the 
passage of the mobile ion. The value of $r$ and $r_{d}$ are constant for a given ion (in our case, $\mathrm{Li}^{+}$) and a given glass composition. Since lithium environment is not changed by the introduction of nitrogen (Fig. 4), it can be concluded that $r_{d}$ is also not affected by the presence of nitrogen.

Equation (2) demonstrates that the strain energy is directly proportional to the value of $G_{o}$. In oxynitride glasses, $G_{o}$ increases with the increase of nitrogen content [29]. We have measured the values of $G_{o}$ for all the glasses studied here and found 32.8, 33.1, 35.0, 35.4 and 35.7 GPa for $0,1.5,3,4.5$ and 6 at $\% \mathrm{~N} /(\mathrm{N}+\mathrm{O})$ respectively. The values of $G_{o}$ were determined using the pulse-echo technique from time-of-flight measurements conducted at room temperature with an estimated accuracy better than $\pm 1 \mathrm{GPa}$. Hence, because of an increase of $G_{o}$, the strain energy is gradually increased with the nitrogen content. In an alternative interpretation, the strain energy $\left(E_{\mathrm{s}}\right)$ required to create a doorway for the diffusion of a mobile ion in a glassy matrix is correlated to the bulk modulus of the glass. Papathanassiou et al. $[30,31]$ have pointed out that the bulk modulus measured at infinitely high frequency governs the relaxation process of supercooled liquids. They suggested that the Gibb's free energy for the diffusion of a species (e.g. $\mathrm{Li}^{+}$) is proportional to the bulk modulus of the super-cooled liquid. In view of above argument, the strain energy can also be proportional to the bulk modulus of the glass.

The electrostatic binding energy $\left(E_{b}\right)$ is the energy required to remove a mobile cation from its non-bridging oxygen site and is given by the following relation [27, 28]

$$
E_{b}=\frac{Z z_{0} e^{2}}{\gamma}\left(\frac{1}{r+r_{0}}-\frac{2}{\lambda}\right)
$$

where $\mathrm{Z}$ and $\mathrm{Z}_{0}$ are the charges of the mobile ions and the corresponding counter ion $\left(\mathrm{O}^{2-}\right) \cdot \mathrm{r}_{0}$ is the ionic radius of the counter ion, oxygen. The covalency parameter, $\gamma$, indicates the degree of charge neutralization between the mobile ion and its immediate neighbors and is similar to the high-frequency limit of the dielectric permittivity $\left(\varepsilon_{\infty}\right)$ [27]. Since the introduction of nitrogen 
into the glass structure increases the dielectric permittivity [26], $\mathrm{E}_{\mathrm{b}}$ decreases with the increase of nitrogen content in the glass matrix.

According to this model, the increased bonding density and network reticulation caused by the formation of the $\mathrm{Si}-\mathrm{N}$ bonds is the source of an increase of the term related to the network strain energy $\left(\mathrm{E}_{\mathrm{s}}\right)$. Moreover, replacement of Si-O bonds by the more covalent Si-N causes a decrease in $E_{b}$. However, a decrease of activation energy $\left(E_{a}\right)$ is experimentally observed with increasing nitrogen content. This decrease provides evidence that $E_{b}$ is counteracted over $E_{s}$ which leads to the effective decrease of $E_{a}$. After considering all possible contributions, the overall effect of nitration on ionic conductivity turns out to be positive.

In this study, the ${ }^{7} \mathrm{Li}$ NMR (Fig. 4) spectra did not show any structural change with nitrogen addition. Hence, we assume that all $\mathrm{Li}^{+}$ions are connected to oxygen before and after nitridation. However, with the introduction of nitrogen into the glass structure, the Li-O-Si-O units are substituted by Li-O-Si-N, which affects the Li-O bonds. Moreover, the combination of Si-N-Si bridge formation with silicon atoms in 4-fold coordination favors the delocalization of the negative charge of both oxygen and nitrogen atoms along the Li-O-Si-N of oxynitride structure. This charge delocalization mechanism withdraws negative charges from the coordination sites of $\mathrm{Li}$ and, thus, leads to weaker electrostatic interactions between glass network and the $\mathrm{Li}^{+}$ions. This situation favors $\mathrm{Li}^{+}$ion dissociation from the silicate structure, thus justifying the observed lower activation energy for conduction.

\section{Conclusions}

We prepared nitrided lithium disilicate glasses containing up to 6 atm $\% \mathrm{~N} /(\mathrm{N}+\mathrm{O})$ by partial substitution of oxygen. The introduction of nitrogen in the -Si-N-Si-network was 
evidenced by FTIR reflection spectroscopy and ${ }^{29} \mathrm{Si}$ solid-state NMR. A gradual change in the $\mathrm{Q}^{\mathrm{n}}$ units of the silicate structure with the progressive substitution of oxygen was observed. The formation of structural units of $\mathrm{SiNO}_{3}, \mathrm{SiN}_{2} \mathrm{O}_{2}$ and $\mathrm{SiN}_{3} \mathrm{O}$ with the addition of nitrogen is evidenced. Nitrogen provides higher connectivity through three coordinated nitrogen, rather than two coordinated oxygen with silicon. The partial substitution of oxygen in lithium disilicate glass decreases the activation energy of ionic conduction, which leads to an increase in the ionic conductivity. This is due to weaker electrostatic interactions between the lithium and oxygen ions. We believe this report provides insight into understanding the mobility of ions and electrical conductivity concerning modifications in the glass structure.

\section{Acknowledgements}

The authors are grateful to the São Paulo Research Foundation (FAPESP), Brazil (\#2013/09093-1 and 2013/07793-6) for the financial support of this research project. The authors are also grateful to Prof. Jean-Louis Souquet for his critical comments.

\section{References}

[1] S. Krüger, J. Deubener, Lag time to crystal nucleation of supercooled lithium disilicate melts: A test of the classical nucleation theory, J. Non-Cryst. Solids 426 (2015) 1-6.

[2] S. Huang, Z. Huang, W. Gao, P. Cao, Structural response of lithium disilicate in glass crystallization, Cryst. Growth Des. 14 (2014) 5144-5151.

[3] J. Habasaki, K. L. Ngai, Molecular dynamics study of heterogeneous dynamics in lithium disilicate crystal, J. Electroceram 34 (2015) 43-56. 
[4] W. Liena, H. W. Roberts, J. A. Platt, K. S. Vandewalle, T. J. Hill and T.-M. G. Chu, Microstructural evolution and physical behavior of a lithium disilicate glass-ceramic, Dent. Mater. 31 (2015) 928-940.

[5] M. M. Mahmouda, D. C. Folz, C. T.A. Suchicital, D. E. Clark, Estimate of the crystallization volume fraction in lithium disilicate glass-ceramics using Fourier transform infrared reflectance spectroscopy, J. Euro. Ceram. Soc. 35 (2015) 597-604.

[6] P. C. Soares Jr., E. D. Zanotto, V. M. Fokin, H. Jain, TEM and XRD study of early crystallization of lithium disilicate glasses, J. Non-Cryst. Solids 331 (2003) 217-227.

[7] V. M. Fokin, E. D. Zanotto, J. W.P. Schmelzer, O. V. Potapov, New insights on the thermodynamic barrier for nucleation in glasses: The case of lithium disilicate, J. NonCryst. Solids 351 (2005) 1491-1499.

[8] M. J. Davis, E. D. Zanotto, Glass-ceramics and realization of the unobtainable: Property combinations that push the envelope, MRS Bull. 42(3) (2017) 195-199.

[9] E. D. Zanotto, A bright future for glass-ceramics, Am. Ceram. Soc. Bull. 89(8) (2010) 19-27.

[10] H. Unuma, T. Kokubo, S. Sakka, Crystallization of Li-Si-O-N oxynitride glasses, J. Mater. Sci. 23 (1988) 4399-4405.

[11] N. Brinkmann, D. Sommer, G. Micard, G. Hahn, B. Terheiden, Electrical, optical and structural investigation of plasma-enhanced chemical-vapor-deposited amorphous silicon oxynitride films for solar cell applications, Solar Energy Mater. Solar Cells, 108 (2013) $180-188$.

[12] J. M. Reau, H. Kahnt, J. Rocherulle, P. Verdier, Y. Laurent, The influence of nitrogen on the mobility of lithium in oxynitride glasses of the Li-Si-AI-O-N system, J. Non-Cryst. Solids 155 (1993) 185-188. 
[13] B. Wang, B.S. Kwak, B.C. Sales, J.B. Bates, Ionic conductivities and structure of lithium phosphorus oxynitride glasses, J. Non-Cryst. Solids 183 (1995) 297-306.

[14] N. Mascaraque, J. L. G. Fierro, A. Durán, F. Muñoz, An interpretation for the increase of ionic conductivity by nitrogen incorporation in LiPON oxynitride glasses, Solid State Ionics 233 (2013) 73-79.

[15] F. Muñoz, A.Durán, L.Pascual, L. Montagne, B. Revel, A. C. M. Rodrigues, Increased electrical conductivity of LiPON glasses produced by ammonolysis, Solid State Ionics 179 (2008) 574-579.

[16] S. P. Singh, A. M. Rodrigues, H. D. Orsolini, P. P. G. Mattos, E. D. Zanotto, J. Rocherullé, P. B. Rocherullé, R. Lebullenger, Crystallization pathways and some properties of lithium disilicate oxynitride glasses, Ceram. Int. 43 (15) (2017) 12348-12356.

[17] G. Qu, Z. Luo, W. Liu, A. Lu, The preparation and properties of zirconia-doped Y-Si-Al-O$\mathrm{N}$ oxynitride glasses and glass-ceramics, Ceram. Internat. 39 (2013) 8885-8892.

[18] S. Ahmadi, B. E.Yekta, H. Sarpoolaky, A. Aghaei, Preparation of monolithic oxynitride glasses by sol-gel method, J. Non-Cryst. Solids 404 (2014) 61-66.

[19] M. Sekine, S. Katayama, Preparation of silicon oxynitride glass fibers by ammonolysis of silica gels, J. Non-Cryst. Solids 134 (1991) 199-207.

[20] A. Nordmann, Y.-B. Cheng, M. E. Smith, Role of nitrides in oxynitride glasses and glassceramics: An NMR Investigation, Chem. Mater. 8 (1996) 2516-2522.

[21] A. Bachar, C. Mercier, A. Tricoteaux, A. Leriche, C. Follet, M. Saadi, S. Hampshire, Effects of addition of nitrogen on bioglass properties and structure, J. Non-Cryst. Solids $358(2012)$ 693-701. 
[22] E. Leonova, A. S. Hakeem, K. Jansson, B. Stevensson, Z. Shen, J. Grins, S. Esmaeilzadeh, M. Eden, Nitrogen-rich La-Si-Al-O-N oxynitride glass structures probed by solid-state NMR, J. Non-Cryst. Solids 354 (2008) 49-60.

[23] K. J. D. MacKenzie, M. E. Smith, Multinuclear solid-state nuclear magnetic resonance of inorganic materials, Pergamon Materials Series, Elsevier, Amsterdam, vol. 6, 2002.

[24] A. Pradel, C. Rau, D. Bittencourt, P. Armand, E. Philippot, M. Ribes, Mixed glass former effect in the system $0.3 \mathrm{Li}_{2} \mathrm{~S}-0.7\left[(1-\mathrm{x}) \mathrm{SiS}_{2}-\mathrm{xGeS}_{2}\right]$ : A structural explanation, Chem. Mater. 10 (8) (1998) 2162-2166.

[25] J. L. Narváez-Semanate, A. C. M. Rodrigues, Microstructure and ionic conductivity of $\mathrm{Li}_{1+x} \mathrm{Al}_{\mathrm{x}} \mathrm{Ti}_{2-\mathrm{x}}\left(\mathrm{PO}_{4}\right)_{3}$ NASICON glass-ceramics, Solid State Ionics 181 (25-26) (2010) 1197-1204.

[26] H. Unuma, S. Sakka, Electrical conductivity in Na-Si-O-N oxynitride glasses, J. Mater. Sci. Lett. 6 (1987) 996-998.

[27] O. L. Anderson, D. A. Stuart, Calculation of activation energy of ionic conductivity in silica glasses by classical methods, J. Am. Ceram. Soc. 37 (1954) 573-580.

[28] A. Shaw, A. Ghosh, Correlation of ion dynamics with characteristic length scales and network structural units in bismuth borate glasses, J. Chem. Phys. 139 (2013) 114503.

[29] J. Rocherulle, J. Guyader, P. Verdier, Y. Laurent, Li-Si-AI-O-N and Li-Si-O-N oxynitride glasses study and characterization, J. Mat. Sci. 24 (1989) 4525-4530.

[30] A. N. Papathanassiou, I. Sakellis, J. Grammatikakis, C. M. Roland, The role of the isothermal bulk modulus in the molecular dynamics of super-cooled liquids, J. Chem. Phys. 135 (2011) 244508. 
[31] Anthony N. Papathanassiou, Ilias Sakellis, Correlation of the scaling exponent of the diffusivity-density function in viscous liquids with their elastic properties, J. Chem. Phys. $132(2010) 154503$. 


\section{$\underline{\text { Research Highlights }}$}

D Nitrided lithium disilicate glasses prepared by partial substitution of $\mathrm{O}_{2}$ by $\mathrm{N}_{2}$

$>$ Incorporation of nitrogen decreases the activation energy for the conduction of $\mathrm{Li}^{+}$

$>$ Increase in the ionic conductivity up to four-fold for the most nitrided glass

$>$ Higher conductivity explained by the Anderson and Stuart model 
